\title{
Treatment of bone tumours by radiofrequency thermal ablation
}

\author{
Fernando Ruiz Santiago • María del Mar Castellano García • \\ Jose Luis Martínez Montes · Manuel Ruiz García • \\ Juan Miguel Tristán Fernández
}

Published online: 7 January 2009

(C) The Author(s) 2008. This article is published with open access at Springerlink.com

\begin{abstract}
Radiofrequency thermal ablation (RFTA) is considered the treatment of choice for osteoid osteomas, in which it has long been safely used. Other benign conditions (chondroblastoma, osteoblastoma, giant cell tumour, etc.) can also be treated by this technique, which is less invasive than traditional surgical procedures. RFTA ablation is also an option for the palliation of localized, painful osteolytic metastatic and myeloma lesions. The reduction in pain improves the quality of life of patients with cancer, who often have multiple morbidities and a limited life expectancy. In some cases, these patients are treated with RFTA because conventional therapies (surgery, radiotherapy, chemotherapy, etc.) have been exhausted. In other cases, it is combined with conventional therapies or other percutaneous treatments, e.g., cementoplasty, offering faster pain relief and bone strengthening. A multidisciplinary approach to the management of these patients is recommended to select the optimal treatment, including orthopaedic surgeons, neurosurgeons, medical and radiation oncologists and interventional radiologists.
\end{abstract}

Keywords Percutaneous radiofrequency ablation . Bone tumours · Intervention

F. R. Santiago · M. del Mar Castellano García

J. L. M. Montes - M. R. García - J. M. T. Fernández

Traumatology Hospital (Ciudad Sanitaria Virgen de las Nieves),

Carretera de Jaen SN, 18013 Granada, Spain

F. R. Santiago $(\square)$

C- Julio Verne 8, 7B, 18003 Granada, Spain

e-mail: ferruizsan@terra.es; ferusan@ono.com

\section{Introduction}

Cancer has traditionally been treated either systemically with chemotherapy or locally with surgery or radiotherapy. Recent advancements in minimally invasive therapies are adding further tools for cancer management, e.g., chemoablation, thermal ablation, percutaneous grafting, acetabuloplasty and vertebroplasty $[1,2]$.

In thermal ablation, tumours are heated to temperatures above $60^{\circ} \mathrm{C}$ until the tumour cells are killed. It can be produced by microwaves, radiofrequency (RF), highintensity ultrasound (US) or laser [3, 4]. Thermal ablation also includes cryotherapy, in which tumour necrosis is achieved by freezing to below $-20^{\circ} \mathrm{C}$ [5].

Image-guided RF thermal ablation (RFTA) is used in interventional oncology to coagulate and destroy tumour tissue by the direct application of RF-generated heat [6]. The term refers to coagulation induction from all electromagnetic energy sources with frequencies less than $30 \mathrm{MHz}$, with most currently available devices functioning in the $375-500 \mathrm{kHz}$ range [7]. It is the most commonly used technology for thermal ablation in bone, liver, kidney, lung, heart, breast, lymph nodes, nerve ganglia and soft tissue.

This article addresses the use of RFTA in the treatment of bone tumours and tumour-like lesions.

Image guidance

Image guidance is critical to the success of this therapy. Computed tomography (CT) is preferred over other imaging techniques (ultrasound [US], magnetic resonance imaging [MR], and fluoroscopy) to treat bone tumours, because it provides faster imaging acquisition and a better anatomic resolution of the bone tissue. 
Image guidance contributes at every stage such as

1. Pre-procedure: assessment of the volume and configuration of the tumour for selection of the appropriate size of active electrode tip and planning of a safe approach to the lesion that avoids sensitive neurovascular structures.

2. Intra-procedure: monitoring of the introductory needles during the procedure and ensuring the correct localization of the non-insulated active tip of the electrode.

3. Post-procedure: follow-up of patients, preferentially by means of MRI after bone treatment in order to minimize their radiation dose. It is also recommended to assure the technical success of the procedure by demonstrating that bone necrosis cover the treated tumour $[6,8]$.

\section{Instrumentation}

The RF device comprises an electric generator connected to a probe or electrode and grounding pads (Fig. 1). An electrical circuit is formed in the patient by placing the electrode tip in the bone lesion and the grounding pads on the thighs. The electric current from the RF generator flows through the electrode into the patient and out through the grounding pads back to the generator. It consists of an alternating current of high-frequency radio waves that pass from the non-insulated electrode tip to the tissue and dissipate their energy as heat, leading to cell death and coagulation necrosis. Heat is produced by resistive forces that produce ionic and molecular agitation in the tissues surrounding the electrode during attempts by the radio waves to return to the ground pads [9].

RF energy is applied with a metal electrode (14-21 G) covered with insulating material except at the tip, with an active tip length of $0.7-3 \mathrm{~cm}$. Many types of electrodes are available: monopolar, with a single electrode; bipolar, with two electrodes; cluster, with three or more closely spaced electrodes of $<1 \mathrm{~cm}$; and umbrella or multitined expandable electrodes, with an array of multiple electrode tines that expand from a larger, centrally positioned needle cannula.

Some electrodes are internally cooled by saline or water that flows in an internal lumen not in direct contact with patient tissues. Perfusion electrodes have small apertures at the active tip that allow fluids to be infused or injected into the tissue before, during or after the ablation procedure [6, 8].

The type of electrode and size of active tip influence the size and morphology of induced tumour necrosis. A rod electrode is usually more appropriate in bone tumour treatment, because it can be inserted through a drilled hole. The distribution of heat around rod monopolar electrodes can be expected to follow a cylindrical contour with rounded edges. Most heat generation is produced in tissues with lower resistance, and tissue resistivity is much higher in cortical than marrow bone. Hence, cortical tissue is
Fig. 1 Instrumentation used in the procedure. $\mathbf{a}$

Radiofrequency generator. b Grounding pads on the thigh of a patient. c Electrode, biopsy trephine and verterbroplasty needle. d Electrode inserted through vertebroplasty cannula in the thigh of a patient

much more resistant to heating and has an insulating effect when intact, protecting surrounding soft tissues and cartilage [9].

At our centre, we use a hammer, vertebroplasty needle $(100 \mathrm{~cm}, 13$ or $10 \mathrm{G})$ and biopsy trephine $(150 \mathrm{~cm}, 13$ or $15 \mathrm{G})$ to reach the bone lesions and open up an entry channel for the electrode (Fig. 1).

\section{Procedure}

The procedure can be performed under general anaesthesia or conscious sedation. Nerve blockage can be used when limbs are involved.

After imaging the whole bone lesion, the appropriate approach route is selected in order to obtain a complete treatment of the bone tumour after the fewest possible ablation sessions. When the route must pass close to sensitive anatomic structures (blood vessels, nerves), the needle is carefully introduced in short steps.

An intramuscular needle is first inserted at the selected site to guide the entry of the thicker vertebroplasty needle. CT monitoring allows any deviations from the route to be corrected, and the needle is placed in the bone up to the edge of the tumour. A biopsy trephine is then introduced to obtain material for the pathology study, creating a channel for the entry of the RF electrode. After the correct insertion of the electrode and without displacing it, the guide cannula is withdrawn as far as possible to avoid its contact with the active electrode tip, which could heat the cannula and burn the pathway and skin.

Immediately afterwards (within 30-60 s), the power output is increased to $90^{\circ} \mathrm{C}$ and dry ablation is performed for $6 \mathrm{~min}$. In large lesions, the vertebroplasty needle is moved to another selected site, repeating the procedure as often as necessary.

A typical RF treatment has an output reading of less than $10 \mathrm{~W}$ and an impedance of less than $150 \Omega$. Once the treatment is completed, the RF electrode is removed and a small dressing is applied to the skin [10].
Bone tumour treatment by RFTA

Image-guided RFTA reduces the pain and improves the function and quality of life of patients with painful bone tumours. It has been used to treat benign bone tumours and tumour-like lesions as a single modality or as an adjunct to surgical therapy. CT-guided radiofrequency or laser ablation is the gold standard procedure for most osteoid osteomas [11].

RF or laser thermal ablation also offers an alternative method for palliation of localized and painful osteolytic metastatic lesions [12]. The reduction in pain that can be obtained improves the quality of life for patients with cancer, who often have multiple morbidities and a limited life expectancy. A multidisciplinary approach to the management of these patients is recommended in order to select the optimal treatment, including orthopaedic surgeons, neurosurgeons, medical and radiation oncologists and interventional radiologists.

\section{Osteoid osteoma}

Osteoid osteoma, first described in 1935 [13], is a benign osteogenic tumour most frequently observed in the cortex of long bones in children and young adults. It is relatively common and accounts for around $10 \%$ of all benign bone tumours [14].

There are three distinct management options: surgery, percutaneous therapy and conservative medical treatment. Although cases of spontaneous regression have been reported [15], the prolonged presence of the tumour may lead to complications, including growth disturbances, scoliosis and osteoarthritis [16]. Medical management used to be appropriate when the alternative was traditional surgical resection. However, RFTA, with its high success rates, low complication rates and short recovery period can now be considered the treatment of choice for most osteoid osteomas located in the appendicular skeleton and pelvis (Fig. 2).
Fig. 2 a Osteoid osteoma located in the anterior cortex of the femoral neck in a child. b Electrode in place and guide cannula withdrawn
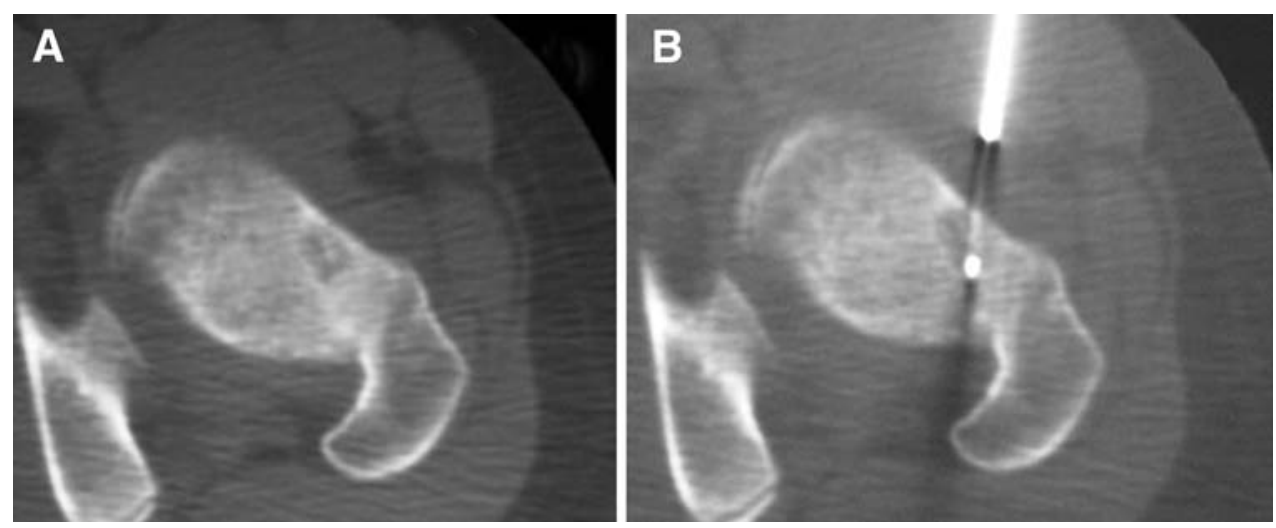
CT-guided RFTA of osteoid osteomas is only indicated when a presumptive diagnosis is made based on history, clinical examination and CT. TC ${ }^{99}$ Scintigraphy also plays an important role in defining an active lesion.

The technical and clinical success of RFTA in osteoid osteomas was first reported by Rosenthal [17] in 1992. Subsequently, most reports on radiofrequency ablation of osteoid osteoma have described clinical success in 73$100 \%$ of patients, with few complications and a short hospital stay $[11,18,19]$. Our experience is limited to 15 cases and clinical success was achieved in 14 (93\%); pain returned in one patient with tibial osteoid osteoma, who subsequently underwent surgery.

Other bone tumour or tumour-like lesions

Other benign bone conditions are also suitable for RFTA treatment, including giant cell tumour, chondroblastoma, osteoblastoma, haemangioma, eosinophilic granuloma and enchondroma.

Chondroblastomas are benign cartilaginous lesions that are usually detected in patients under 20 years old. They generally grow at the epiphysis or apophysis of the immature skeleton, hampering surgical removal, and RFTA has been reported as an alternative curative therapy in these cases [20, 21] (Fig. 3). Unlike osteoid osteomas, there is a tendency to progression.

Erickson et al. described the first application of RFTA in three cases of chondroblastomas, finding no evidence of recurrence in follow-up periods ranging from 2 to 4 years [21]. We are aware of three subsequent studies on the successful treatment of chondroblastomas with RFTA. The first reported on four young patients and described an association between lesion size and articular collapse, which was observed in two of them [20]. The second described the avoidance of articular collapse by the combined use of RFTA and bone grafting [22]. The third reported that a patient with chondroblastoma at the greater tuberosity of the humerus was asymptomatic at 6 months [23].Our experience is limited to two cases, in which RFTA was combined with percutaneous cementation (Fig. 3). The patients remain asymptomatic more than 2 years later.

Osteoblastoma is a rare, benign, bone-forming tumour that is histologically related to the more common osteoid
Fig. 3 a CT scan of a chondroblatoma of distal femoral epiphysis. b Biopsy trephine within tumour. c Electrode within tumour. d Radiography of lesion after ablation and cementation
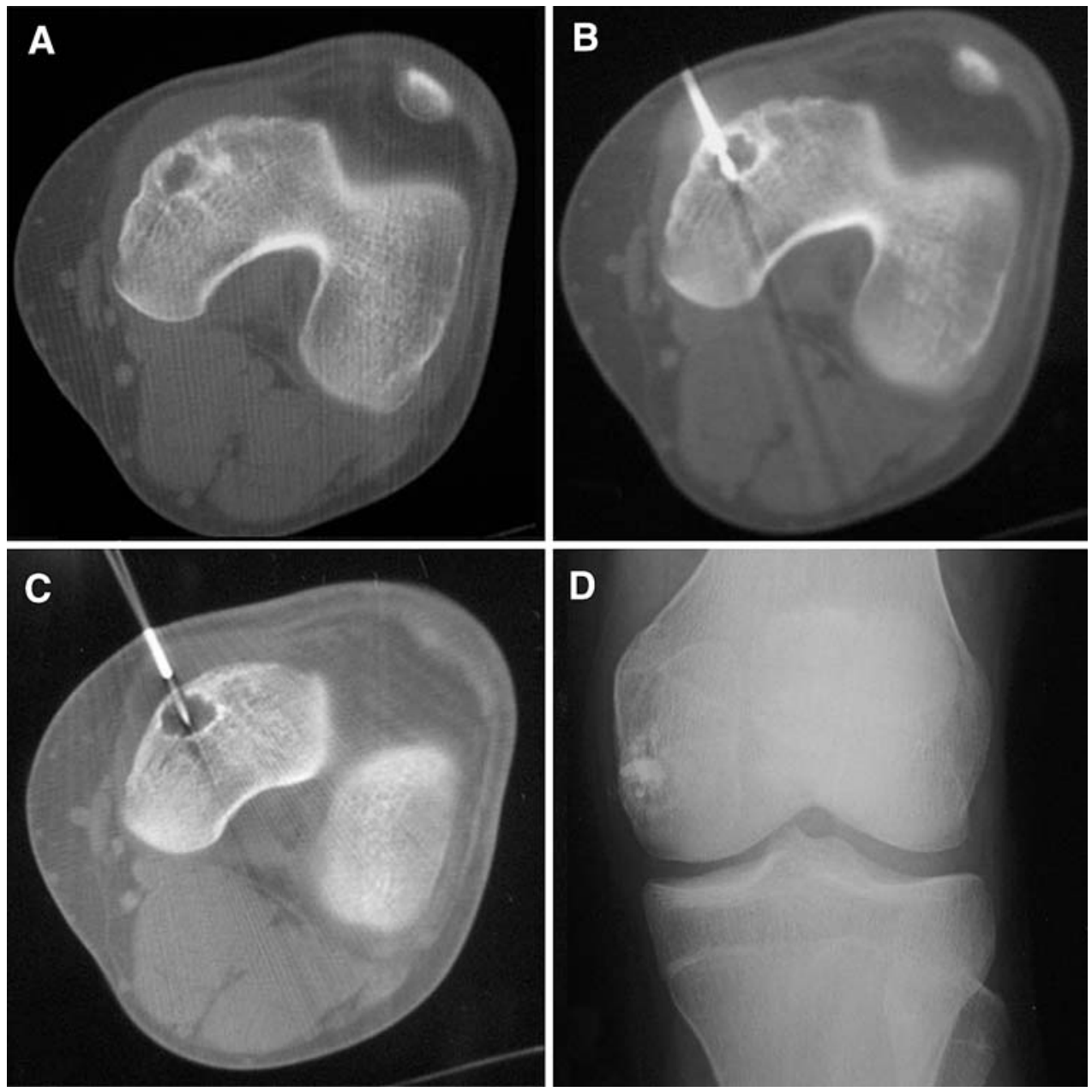
osteoma. Almost $90 \%$ of patients are diagnosed before 30 years of age. Despite its benign nature, this tumour can exhibit aggressive behaviour and become larger than an osteoid osteoma ( $\geq 2 \mathrm{~cm}$ ) (Fig. 4). Recurrences are not uncommon after classic treatment by surgical excision or curettage [24]. RFTA is a less invasive alternative and performed in the same way as for osteoid osteomas, using electrodes with a longer active tip or a greater number of ablation sessions or multi-tip array probes [25].

There are fewer published reports on the treatment of other benign bone conditions such as giant cell tumour, enchondroma, eosinophilic granuloma and bone haemangioma. However, we have used RFTA to treat patients with these diagnoses at our centre, obtaining good pain control and detecting no growth in follow-up studies.

One study described the treatment of two intracortical chondromas, preoperatively misdiagnosed as osteoid osteomas and treated with RFTA. Radiofrequency appears to have cured the tumour in one patient, whereas the other required surgery [26].

There has been a very recent report of technical and clinical success in treating two patients with solitary eosinophilic granuloma of bone [27].

The gold standard treatment of giant cell tumour is extended curettage. Use of an adjuvant therapy such as phenol, liquid nitrogen or argon beam coagulator may help to reduce the risk of local recurrence. The created defect should be carefully filled with impacted, antibiotic-laden, morcellized graft bone from the bone bank [28, 29]. Adjuvant therapy plays a major role when the localization of the tumour makes complete surgical resection challenging. Cryosurgery was used to treat a sacral giant cell tumour with a good outcome [30]. We have treated one patient with an unresectable sacral giant tumour using partial RFTA and cementation, obtaining pain palliation and improvement in the quality of life (reduction in pain of $\geq 4$ points on a visual analogue scale) during 2 years of follow-up. Therefore, we consider that RFTA should be included among adjuvant therapies for giant cell tumours.
There are many therapeutic modalities to treat bone hemangioma: selective embolization, radiotherapy, cementation, alcohol ablation and surgery. The selection of modality depends on the radiological findings and clinical status. We have treated a cortical tibial hemangioma with RFTA, achieving pain control and growth inhibition at 1 year of follow-up. We have found one report in the literature on the RFTA treatment of multiple lesions of multifocal epithelioid hemangioendothelioma, an uncommon low-grade malignant vascular neoplasm, with no evidence of recurrence after a long follow-up [31]. We therefore believe that RFTA can be added to the armamentarium for treating vascular bone tumours, in isolation or combined with other techniques. RFTA has proven useful to treat vascular tumours of the liver [32].

Metastases and myeloma

Although bone metastases can be produced by any cancer, they largely derive from breast, prostate, kidney, lung, pancreatic, colorectal, stomach, thyroid and ovarian tumours. The spine is the most frequently involved area, followed by the pelvis, hip, femurs, ribs and skull [33].

Plasmocytoma and myeloma are haematological malignancies that cause skeletal destruction with osteolytic lesions and/or pathological fractures. Two-thirds of patients with myeloma complain of bone pain, which is frequently located in regions subjected to constraint, e.g., the back, long bones or pelvis. Although external beam radiation therapy is the current gold standard treatment for cancer patients with localized bone pain, $20-30 \%$ of patients do not experience pain relief with this approach [12]. Radiation treatment can also result in additional early bone loss due to inflammation, and limited weight bearing should be recommended during radiation to prevent pathological fractures. Other treatment options for these patients include localised (surgery), systemic (chemotherapy, hormonal therapy, radiopharmaceuticals and bisphosphonates) and analgesic (opioids and non-steroidal anti-inflammatory
Fig. 4 Osteoblastoma of iliac wing. a CT scan showing $2-\mathrm{cm}$ lytic lesion. b Electrode in place during ablation
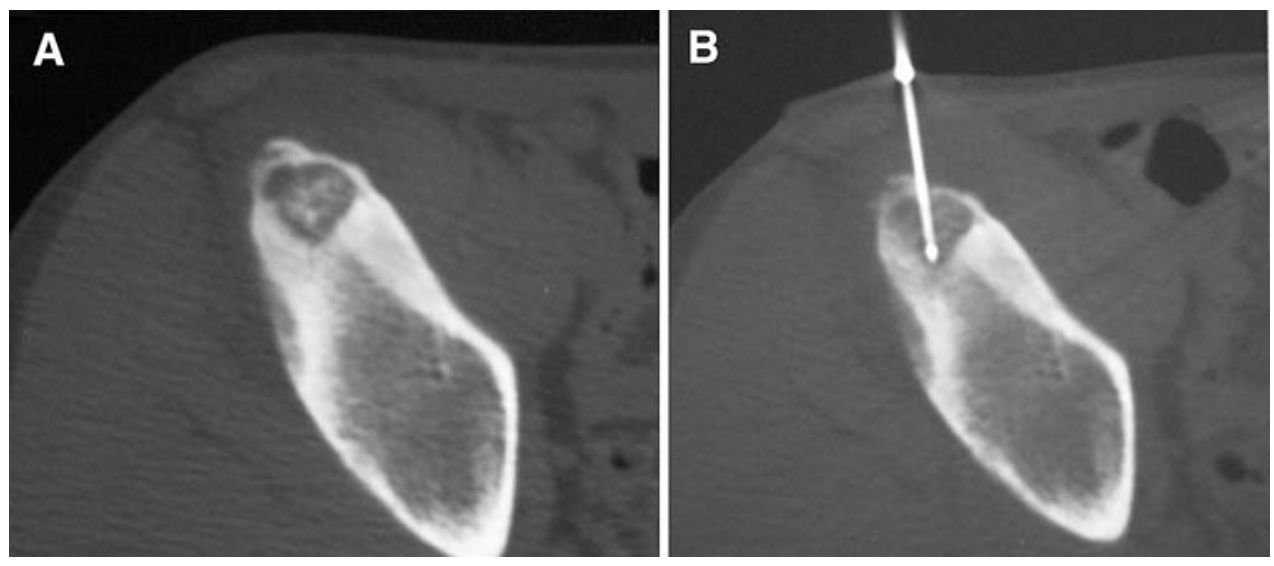
drugs) therapies $[34,35]$. However, conventional therapies are often unsuccessful in providing total pain relief, and many patients continually require significant increases in the dose of their narcotic medications. The quality of life and functional capacity of these patients are frequently compromised.

Considering that the life expectancy of most patients with bone metastases is limited and that around 1220 weeks are usually required before maximum benefit is obtained from post-radiation therapy [34], the aim must be to provide the earliest possible pain relief.

RFTA can be used as an alternative to these treatments $[4,36]$. Dupuy et al. were the first to report pain relief using RF ablation of bone metastases [28]. Many subsequent studies have described RF ablation as a useful tool to relieve disabling pain $[4,12]$, observing good outcomes at a few days or weeks after the procedure (Figs. 5-6). RFTA can also contribute to local control of tumour growth and can even be used as the definitive treatment for small solitary lesions [37].

Monopolar electrodes with a longer active tip can be used in more extensive bone lesions, although expandable type electrodes are recommended by some authors when the osteolysis is large enough to allow the deployment of multiple tines [4].

Its utilization in combination with other procedures, e.g., cementoplasty, is sometimes indicated to reinforce bone structures and stabilize bones at high risk of pathologic fracture [38]. The prior use of RFTA theoretically facilitates cementation by destroying tissue and forming the cavity required for the injected cement to fit the necrotic space, reducing the risk of leakage and avoiding the displacement of tumour tissue usually observed when cementation is used as single procedure [39]. Bone cement generates heat up to $80^{\circ} \mathrm{C}$, which may help to potentiate the anticancer effects of RFTA [40].

Pain relief is achieved within 4 weeks in $82-97 \%$ of patients treated with vertebroplasty and in $90-100 \%$ of patients treated with RF ablation. Success may be increased with a combination of the two procedures [40].

\section{Complications}

This ablation technique is contraindicated in patients with cardiac pacemakers, because RF generators can cause undesirable physiological effects [9].

Possible complications of RF ablation include bleeding, infection, pathological fractures, injury to adjacent neural structures, abscess formation and skin and muscle burns. These burns have been described at the cannula entry pathway and grounding pads $[4,12]$.

In weight-bearing joints and lesions near the articular cartilage, there is a risk of cartilage damage and mechanical weakening of the bone [20].
Fig. 5 Multiple myeloma. a CT scan shows lytic lesion in femoral neck. b Electrode in place. c CT during cementation. d Radiography after ablation and cementation
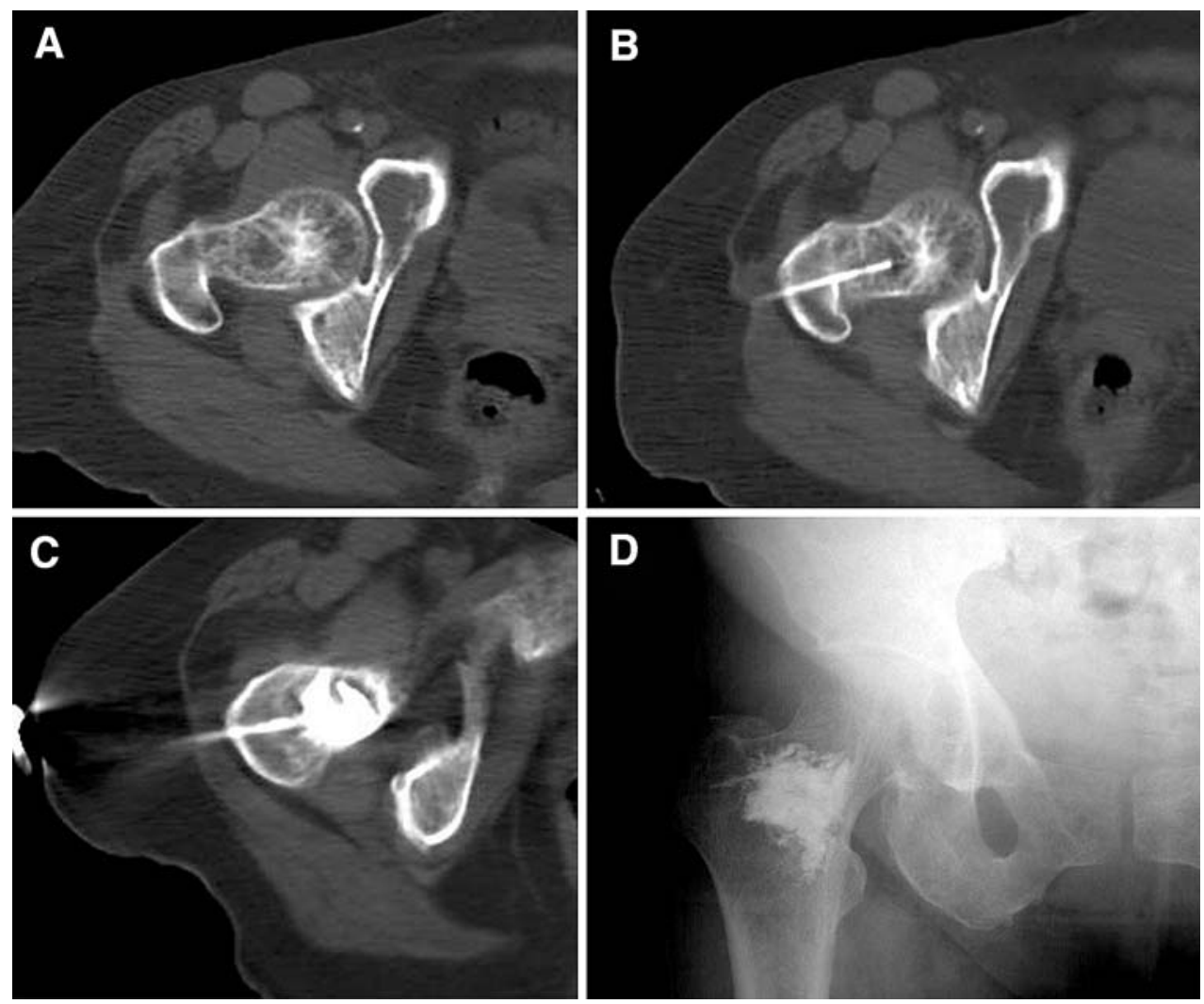
Fig. 6 Metastatic lytic lesion of right acetabulum in patient with thyroid cancer. a Axial CT scan of lesion b Electrode in place during ablation
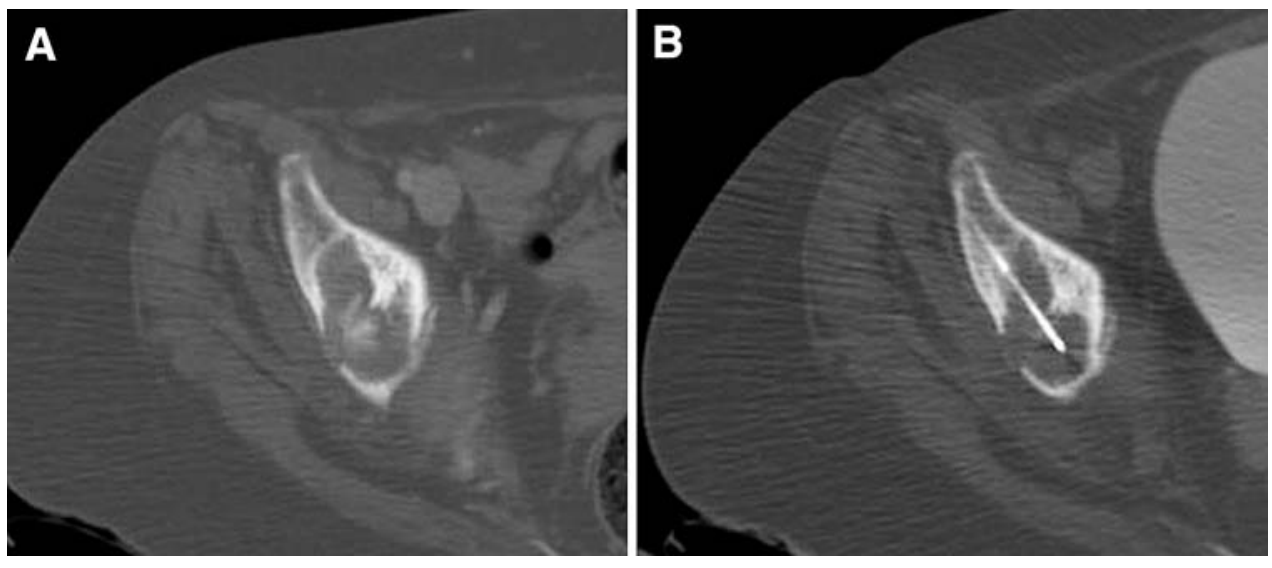

Care should be taken in vertebral lesions when tumours invade the posterior cortex because of the risk of thermal damage to nerves. The heating of tissue to $45^{\circ} \mathrm{C}$ in RFTA is cytotoxic to spinal cord and peripheral nerves [41]. Thermometry may be necessary to avoid nerve injury, placing a thermocouple near the thecal sac or peripheral nerves [28].

\section{Conclusions}

Several ablation techniques are available to treat bone tumours. They offer multiple advantages. They are minimally invasive, allow targeted tumour destruction and have a low rate of complications. To date, the most widely utilized techniques are cryosurgery and RFTA. However, cryotherapy usually requires open surgery while RFTA can be performed percutaneously.

RFTA of bone tumours is appropriate when there is a clear advantage (less invasive, shorter recovery) over surgery or when surgery would not be feasible (e.g., multiple or unresectable lesions). RFTA is most frequently used for bone osteoid osteoma and metastases and has become the gold standard treatment for osteoid osteoma. The outcomes are excellent and superior to the results of conventional management.

In metastases, it may be used as a curative therapy in small, solitary tumours or as palliative treatment in isolation or combined with other modalities such as surgery, radiotherapy or cementation.

Further indications are now emerging, with reports of good outcomes in treating other primary bone tumours.

Open Access This article is distributed under the terms of the Creative Commons Attribution Noncommercial License which permits any noncommercial use, distribution, and reproduction in any medium, provided the original author(s) and source are credited.

\section{References}

1. Hierholzer J, Anselmetti G, Fuchs H, et al. Percutaneous osteoplasty as a treatment for painful malignant bone lesions of the pelvis and femur. J Vasc Interv Radiol. 2003;14:773-7.

2. Schaefer O, Lohrmann C, Markmiller M, et al. Combined treatment of spinal metastasis with radiofrequency heat ablation and vertebroplasty. AJR. 2003;180:1075-7.

3. Witt JD, Hall-Craggs MA, Ripley P, et al. Interstitial laser photocoagulation for the treatment of osteoid osteoma. J Bone Joint Surg Br. 2000;82:1125-8.

4. Goetz MP, Callstrom MR, Charboneau JW, et al. Percutaneous image-guided radiofrequency ablation of painful metastases involving bone: a multicenter study. J Clin Oncol. 2004;22(2):300-6.

5. Silverman SG, Tuncali K, Adams DF, et al. MR imaging-guided percutaneous cryotherapy of liver tumors: initial experience. Radiology. 2000;217:657-64.

6. Goldberg SN, Grassi CJ, Cardella JF, et al. Image-guided tumor ablation: standardization of terminology and reporting criteria. Radiology. 2005;235:728-39.

7. Goldberg SN, Dupuy DE. Image-guided radiofrequency tumor ablation: challenges and opportunities-part I. J Vasc Interv Radiol. 2001;12:1021-32.

8. Goldberg SN, Grassi CJ, Cardella JF, et al. Image-guided tumor ablation: standardization of terminology and reporting criteria. $\mathrm{J}$ Vasc Interv Radiol. 2005;16:765-78.

9. Pinto CH, Taminiau AHM, Vanderschueren GM, et al. Technical considerations in CT-guided radiofrequency thermal ablation of osteoid osteoma: tricks of the trade. AJR. 2002;179:1633-42.

10. Rachbauer F, Mangat J, Bodner G, et al. Heat distribution and heat transport in bone during radiofrequency catheter ablation. Arch Orthop Trauma Surg. 2003;123:86-90.

11. Rosenthal DI, Hornicek FJ, Torriani M, et al. Osteoid osteoma: percutaneous treatment with radiofrequency energy. Radiology. 2003;229:171-5.

12. Callstrom MR, Charboneau JW, Goetz MP, et al. Image-guided ablation of painful metastatic bone tumors: a new an effective approach to a difficult problem. Skeletal Radiol. 2006;35:1-15.

13. Jaffe HL. Osteoid osteoma: a benign osteoblastic tumor composed of osteoid and atypical bone. Arch Surg. 1935;31:709-28.

14. Greenspan A. Benign bone-forming lesions: osteoma, osteoid osteoma, and osteoblastoma. Clinical, imaging, pathologic, and differential considerations. Skeletal Radiol. 1993;22:485-500.

15. Simm RJ. The natural history of osteoid osteoma. Aust NZJ Surg. 1975;45:412-5. 
16. Haibach H, Farrell C, Gaines RW. Osteoid osteoma of the spine: surgically correctable cause of painful scoliosis. CMAJ. 1986; 135:895-9.

17. Rosenthal DI, Alexander A, Rosenberg AE, et al. Ablation of osteoid osteomas with a percutaneously placed electrode: a new procedure. Radiology. 1992;183:29-33.

18. Lindner NJ, Ozaki T, Roedl R, et al. Percutaneous radiofrequency ablation in osteoid osteoma. J Bone Joint Surg Br. 2001;83: 391-6.

19. Torriani M, Rosenthal DI. Percutaneous radiofrequency treatment of osteoid osteomas. Pediatr Radiol. 2002;32:615-8.

20. Tins B, Cassar-Pullicino V, McCall I, et al. Radiofrequency ablation of chondroblastoma using a multi-tined expandable electrode system: initial results. Eur Radiol. 2006;14(6):804-10.

21. Erickson JK, Rosenthal DI, Zaleske DJ, et al. Primary treatment of chondroblastoma with percutaneous radiofrequency heat ablation: report of three cases. Radiology. 2001;221:463-8.

22. Petsas T, Megas P, Papathanassiou Z. Radiofrequency ablation of two femoral head chondroblastomas. Eur J Radiol. 2007;63:63-7.

23. Sivan M, Theologis TN, Athanasou NA, et al. Percoutaneous radio-frequency ablation of chondroblastoma: an effective alternative. Eur J Surg Traumatol. 2007;17:93-5.

24. Frassica FJ, Waltrip RL, Sponseller PD, et al. Clinicopathologic features and treatment of osteoid osteoma and osteoblastoma in children and adolescents. Orthop Clin North Am. 1996;27: 559-74.

25. DiCaprio MR, Bellapianta JM. Use of radiofrequency ablation in the treatment of bone tumors. Tech Orthop. 2007;22(2):99-109.

26. Ramnath RR, Rosenthal DI, Cates J, et al. Intracortical chondroma simulating osteoid osteoma treated by radiofrequency. Skeletal Radiol. 2002;31:597-602.

27. Corby RR, Stacy GS, Peabody TD, et al. Radiofrequency ablation of solitary eosinophilic granuloma of bone. AJR. 2008;190:1492-4.

28. Simon CJ, Dupuy DE. Percutaneous minimally invasive therapies in the treatment of bone tumors: thermal ablation. Semin Musculoskelet Radiol. 2006;10(2):135-42.

29. Gibbs CP, Lewis VO, Peabody T. Beyond bone grafting: techniques in the surgical management of benign bone tumors. Instr Course Lect. 2005;54:497-503.
30. Althausen PL, Schneider PD, Bold RJ, et al. Multimodality management of a giant cell tumor arising in the proximal sacrum: case report. Spine. 2002;27(15):E361-5.

31. Rosenthal DI, Treat ME, Mankin HJ, et al. Treatment of epithelioid hemangioendothelioma of bone using a novel combined approach. Skeletal Radiol. 2001;30:219-22.

32. Hinshaw JL, Laeseke PJ, Weber SM, et al. Multiple-electrode radiofrequency ablation of symptomatic hepatic cavernous hemangioma. AJR. 2007;189:W146-9.

33. Nielsen OS, Munro AJ, Tannock IF. Bone metastases: pathophysiology and management policy. J Clin Oncol. 1991;9:509-24.

34. Janjan NA. Radiation for bone metastases: conventional techniques and the role of systemic radiopharmaceuticals. Cancer. 1997;80(8 Suppl):1628-45.

35. Bloomfield DJ. Should bisphosphonates be part of the standard therapy of patients with multiple myeloma or bone metastases from other cancers? An evidence-based review. J Clin Oncol. 1998;16:1218-25.

36. Callstrom MR, Charboneau JW, Goetz MP, et al. Painful metastases involving bone: feasibility of percutaneous CT- and USguided radio-frequency ablation. Radiology. 2002;224:87-97.

37. Link TM, Mayo R, O’Donnell RJ. Radiofrequency ablation-an alternative for definitive treatment of solitary bone metastases. Eur Radiol. 2007;17:3012-3.

38. Nakatsuka A, Yamakado K, Maeda M, et al. Radiofrequency ablation combined with bone cement injection for the treatment of bone malignancies. J Vasc Interv Radiol. 2004;15:707-12.

39. Dupuy DE, Hong R, Oliver B, et al. Radiofrequency ablation of spinal tumors: temperature distribution in the spinal canal. AJR. 2000;175:1263-6.

40. Schaefer O, Lohrmann C, Herling M, et al. Combined radiofrequency thermal ablation and percutaneous cementoplasty treatment of a pathologic fracture. J Vasc Interv Radiol. 2002;13:1047-50.

41. Wong G. Plasma-mediated radiofrequency ablation assisted percutaneous cement injection for treating advanced malignant vertebral compression fractures. AJNR. 2007;28:700-5. 